Int. J. Dev. Biol. 61: 565-570 (2017)

doi: $10.1387 / \mathrm{ijdb} .170055 \mathrm{xx}$

\title{
Molecular cloning and expression analysis of Sox3 during gonad and embryonic development in Misgurnus anguillicaudatus
}

\author{
XIAOHUA XIA, WEIRAN HUO, RUYAN WAN, LINXIA ZHANG, XIAOPEI XIA and ZHONGJIE CHANG* \\ College of Life Science, Henan Normal University, Xinxiang, Henan, People's Republic of China
}

\begin{abstract}
Sox 3 is a single-exon gene located on the $X$ chromosome in most vertebrates. It belongs to the SoxB1 subfamily, which is part of the larger Sox family. Previous studies have revealed that Sox3 is expressed in many fish species. However, how Sox3 influences the development of Misgurnus anguillicaudatus remains unknown. In this study, a Sox 3 homologue, termed MaSox3, was cloned from the brain of $M$. anguillicaudatus using homology-based cloning and the rapid amplification of cDNA ends method. Sequence analysis reveals that MaSox 3 encodes a hydrophilic protein, which contains a characteristic HMG-box DNA-binding domain of 79 amino acids, and shares high homology with Sox3 in other species. Additionally, quantitative real-time reverse transcription PCR and in situ hybridization showed that MaSox 3 is consistently expressed during embryogenesis, with peak expression during the neurula stage and broad expression in the central nervous system. Moreover, tissue distribution analyses have revealed that MaSox3 is abundant in the adult brain, the particle cell layer, and the gonad. Additionally, its expression is observed in primary spermatocyte cells, primary oocytes and previtellogenic oocyte cells. Taken together, all of these results suggest that the expression of the MaSox 3 gene is highly conserved during vertebrate evolution and involved in a wide range of developmental processes including embryogenesis, neurogenesis and gonad development.
\end{abstract}

KEY WORDS: Misgurnus anguillicaudatus, Sox3, embryogenesis, neurogenesis, gonad development

The Sox gene family encodes a large suite of proteins that share over $50 \%$ amino acid sequence identity in their HMG-type DNA-binding domain, a domain associated with the mammalian sex determining gene, sex determining region, $Y$ chromosome (Sry; Sinclair et al., 1990). The proteins belonging to this family are primarily characterized as chromatin associated protein or transcription factors that use their HMG domain to bind the minor groove of DNA in order to aid in the recruitment and binding affinity of various co-factors to specific DNA regions (Watanabe et al., 2016). In recent years, a series of Sry-related HMG box (Sox) genes have been identified in vertebrates, insects and nematodes, and divided into 10 groups, based on their amino acid sequences (Sox A-J.; Bowles et al., 2000).

Sox3 is a single-exon gene, belongs to the SoxB1 (Sox1, Sox2, Sox3 and Sox19) subfamily. It is located on the $X$ chromosome of most vertebrates and contains a highly conserved $\mathrm{N}$-terminal
HMG-domain and C-terminal domain. Previous work has demonstrated that SOX3 acts as a transcriptional activator for two other SoxB1 family members, Sox2 and Sox3 (Kamachi et al., 1998). In addition, Sox3 is widely expressed in the early central nervous system of vertebrates and displays some functional redundancy during development with other Sox genes (Cheah and Thomas, 2015). Sox3 is considered an ancestral precursor of the gene Sry, which is required for sex differentiation and gonadal development (Weiss et al., 2003). In mice, Sox3 expression may affect similar developmental pathways as Sry; Sox3 gain-of-function triggers male sex reversal in the uncommitted XX gonad, whereas lossof-function blocks early spermatogenesis in the postnatal testes germ cells (Laronda and Jameson, 2011).

Abbreviations used in this paper: PCR, polymerase chain reaction. *Address correspondence to: Zhongjie Chang. Molecular and Genetic Laboratory, College of Life Science, Henan Normal University, 46\# East of Construction
Road, Xinxiang, Henan 453007, P. R. China. Tel: +86-373-3326553. E-mail: $13837331530 @ 163 . c o m$ (iD) http://orcid.org/0000-0001-5357-0048

Supplementary Material (3 figures) for this paper is available at: http://dx.doi.org/10.1387/ijdb.170055xx

Submitted: 7 March, 2017; Accepted: 17 October, 2017.

ISSN: Online 1696-3547, Print 0214-6282 
MaSOX3 MYMMMETEIKSPLPQSNT-AAGGKNSSANDQDRVKRPMNAFMVWSRGQRRKMAQENPKMHNSEISKRLGADWKLLTDAEKRPFIDEAKRLRAMHMKEHPDYK RPRRKTKTLLKKDKYSLPGGLLAHG CbSOX3 MYSMMETELKSPLPQSNAGSGPGGKSGGGSDQDRVKRPMNAFMVWSRGQRRKMAQENPKMHNSEISKRLGADWKLLTDAEKRPFIDEAKRLRAMHMKEHPDYK RPRRKTKTLLKKDKYSLPGGLLAPG DrSOX3 MYNMMETEIKSPIPQSNTGSVTGGKNNSANDQDRVKRPMNAFMVWSRGQRRKMAQENPKMHNSEISKRLGADWKLLTDAEKRPFIDEAKRLRAMHMKEHPDYK RPRRKTKTLLKKDKYSLPGGLLAPG CaSOX3 MYSMMETEIKSPLPQSNS--VAGGKNNSSNDQDRVKRPMNAFMVWSRGQRRKMAQENPKMHNSEISKRLGADWKILTDAEKRPF IDEAKRLRAMHMKEHPDYKKRPRRKTKTLLKKDKYSLPGGLLAPG AsSOX3 MYSMMETEIKTPLPQSGSA--QGAKNNSVSDQERVKRPINAFMVWSRGQRRKMAQENTKMHNSEISKRLGADWKLLTDAEKRPFIDEAKRLRAMHMKEHPDYKKRPRRKTKTLLKKDKYSLPGGLLAPG TrSOX3 MYNMMETEIKGPRSRSPIRARRRAGRTTSSNEDRVKRPMNAFMVWSRGQRRKMAQENPKMHNSEISKRLGADWKLLTDAEKRPFIDEAKRLRAMHMKEHPDYK RPRRKTKTLLKKDKYSLPGGLLAPG $* * . * * * * * * * \quad: *$ .$:: * * * * * * * * * * * * * * * * * * * * * * * * * * * * * * * * * * * * * * * * * * * * * * * * * * * * * * * * * * * * * * * * * * * * * * * * * * * * * * * * * * * * * * * * * * * * * * * * * * * * *$ $\leftarrow<$

MaSox3 ATAVNNAVSVG-QRME-YTHM-NGWTNSAYSLMQDQLAYPQHPSMNSP-QIQQMHRYPM-AGLQYPMMSTAQTYMNAASTYS-MSPAYTQQTSSAMGLGS IASVCKTEPSSPPPAITSHSQRACLGDLR CbSOX3 AGAVNSAVSVGHQRMDGYAHVANGWTNGAYSLVQEQLAYPQHHGMSSPPPLQQMHRYDMTAGLQYPMMSTAQTYMSAASTYSGV--SYAQQSPGAVGLGSVASVCKTEPSSPPPAIASHSQRACLGDLS

DrSOX3 ANAVNNAVSVG-QRMD-YTHM-NGWTNSAYSLMQDQLAYPQHPSMNSP-QIQQMHRYPM-AGLQYPMMSTAQTYMNAASTYSSMSPAYTQQTSGAMGLGSMASVCKTEPSSPPPAITSHSQRACLGDLR

CaSOX3 ATAVNSAVSVG-QRMD-YTHM-NGWTNSAYSLMQDQLAYPQHPSMNSS-QLQQMHRYDM-AGLQYPMMSTAQTYMNAASTYS-MSPAYTQQTSSAMGLGSIASVCKTEPSSPPPAITSHSQRACLGDLR AsSOX3 ANAVNNSVSVG-QRMDGYAHM-NGWTNSAYSLMQDQLAYPQHHSMNSP-QIQQMHRYEM-AGLQYPMMSSAQTYMNAASTYS-MSPAYTQQTGSAMGLSSMASVCKTEPSSPPPAITSHSQRACLGDLR

TrSOX3 ANPVNNSVSVG-QRMDGYAHM-NGWTNSAYSLMQDQLAYPQHHNMNSP-QIQQMHRYEM-AGLQYPMMSSAQTYMNAASTYS-MSPAYTQQTPSAMGLSSMASVCKTEPSSPPPAITSHSQRACLGDLR

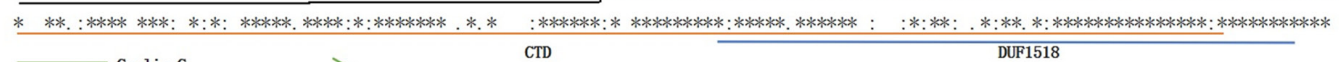
127 129 129 127 127 129 250 256 253 250 251 253

Fig. 1. Alignment of Sox3 protein sequences. The identical, highly

MaSOX3 DMISMYLPPGGDSADHSSLQSSRLHSVHPHYQSAGTGVNGTLPLTHI 297 CbSox3 DMISMYLPPGGDSADHNTLQSSRLHSVHPHYQSAGTGVNGTLPLTHI 303 DrSOX3 DMISMYLPPGGDSADHSSLQTSRLHSVHPHYQSAGTGVNGTLPLTHI 300

CaSox3 DMISMYLPPGGDSADHASLQSSRLHSVHPHYQSAGTGVNGTLPLTHI 297

AsSOX3 DMISMYLPPGGDSEHSSLQSSRLHSVHPHYTAGTAVNGTLPLTHI 298

TrSox3 DMISMYLPPGGDSAEHSSLQSSRLHSVHPHYQTAGTGVNGTLPLTHI 300 ****************:*:**:************:***, *********** conserved and less conserved amino acid residues were indicated by asterisk, colon and dot, respectively. The HMG (high mobility group) box domain is shaded in yellow and the SOXp (SOX transcription factor) domain is boxed. The specificity amino acids were also indicated by arrowheads and underlines. The GenBank accession numbers for the Sox 3 sequences used for alignment are as follows: M. anguillicaudatus (MaSox3), Clarias batrachus (CbSox3): AlZ03370.1, Danio rerio (DrSox3): BAD 11369.2, Carassius auratus (CaSox3): ABM55677.1, Acanthopagrus schlegelii (AsSox3): ABQ96860.1 and Takifugu rubripes (TrSox3): AAQ18496.1.
Fishes are the most diverse and species-rich group of vertebrates, serving as an evolutionary link between invertebrate and vertebrates. For instance, research relating to teleost fish has provided several clues to the molecular evolution process of vertebrates. In specific gain- and loss-of-function experiments using the teleost, zebrafish have help to elucidate the role of Sox3 in both neural

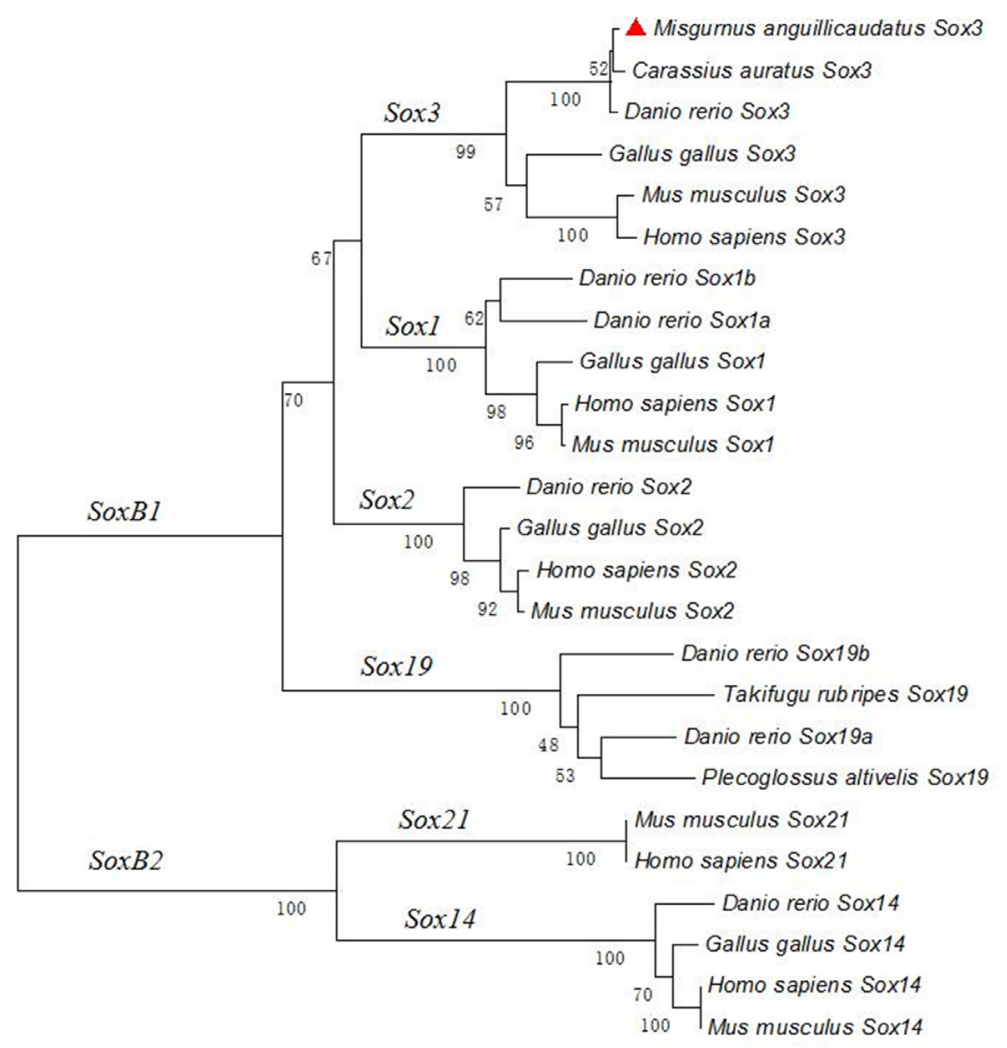

fate determination and differentiation (Dee et al., 2008). In Clarias batrachus, dynamic expression pattern of Sox3 in the gonad confirms its potential role in development and germ cell differentiation (Rajakumar and Senthilkumaran, 2014). To further investigate the evolution and functions of Sox3 in fish development, we decided to analyze the role of Sox3 in critical developmental processes, including sex determination and differentiation processes. Misgurnus anguillicaudatus (Cypriniformes; Cobitidae), a widely distributed teleost native to the eastern coasts of the Asian continent. Specifically, we have quantified expression profiles of Sox3 during early embryo development and in diverse adult tissues, and analyzed of its cellular distribution in the brain, ovary and testis. These results are necessary to provide fundamental information on both the functional and evolutionary role of Sox3 across different species.

\section{Results}

\section{Cloning and sequence analysis of MaSox3}

To clone MaSox 3 from the brain tissue of $M$. anguillicaudatus, we used degenerate primers and the rapid amplification of cDNAends (RACE) strategy. The MaSox3gene (GenBank:

Fig. 2. Phylogenetic tree of MaSox3 in comparison with SoxB proteins in other representative vertebrates using predicted amino acid sequences. Sox 14 and Sox21, belonging to the SoxB2 subgroup were used as outgroup. The numbers in the branches represent the boot-strap value from 1000 replicates obtained using the neighborjoining method. The scale bar is 0.05. The GenBank accession numbers are as follows: Homo sapiens: Sox1, NP_005977.2; Sox2, NP_003097.1; Sox3, NP_005625.2; Sox14, NP_004180.1; Sox21, NP_009015.1; Mus musculus: Sox1, NP_033259.2; Sox2, NP_035573.3; Sox3, NP_033263.2; Sox14, NP_035570.1; Sox21, NP_808421.1; Gallus gallus: Sox1,NP_989664.1; Sox2, NP_990519.2; Sox3, NP_989526.1; Sox14, NP_990092.1; Danio rerio: Sox1a, NP_001002483.1; Sox1b, NP_001032751.1; Sox2, NP_998283.1; Sox3, NP_001001811.2; Sox19a, NP_570983.2; Sox19b, NP_571777.1; Sox14, NP_001032769.1; Takifugu rubripes: Sox19, AAQ18497.1; Plecoglossus altivelis: Sox19, AHK05948.1; Carassius auratus: Sox3, ABM55677.1. 
KY704873) is 1863 bp in length and contains a putative open reading frame that encodes a 297 amino acids (AA) protein (Supplementary Fig. 1). The predicted MASOX3 protein is approximately $33.1 \mathrm{kD}$ with a theoretical isoelectric point of 9.63. Furthermore, the protein structure is composed of $40.40 \%(120 \mathrm{AA})$ alpha helices $8.75 \%$ (26 AA) extended strands, $8.08 \%$ (24 AA) beta turns, and $42.76 \%$ (127 AA) random coils (Supplementary Fig. 2). The structure analysis also revealed that the MASOX3 protein has three alpha helix structure and two random coil structures (Supplementary Fig. 3).

\section{Homology and phylogenetic analysis}

Similar with other species, MASOX3 has the conserved HMG-type DNA-binding domain (Fig. 1), as well as other conserved putative functional domains, such as CYCLIN domain. The Neighbor-joining tree analysis shows MaSox 3 was closely clustered with the Carassius auratus Sox 3 homologues, then with the Danio rerio Sox3 homologue (Fig. 2), which is consistent with the classification and evolutionary status for these species.

\section{Hydropathy analysis}

The hydropathy profile of the MASOX3 protein was determined by ProtScale program which dem-

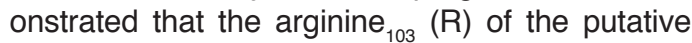
MASOX3 protein exhibits the highest degree of hydrophilicity (hydrophobic parameter: -3.332), whereas isoleucine $_{222}(\mathrm{I})$ exhibits the highest degree of hydrophobicity (hydrophobic parameter: 1.600) (Fig. 3A). In totality, the SOX3 protein contained more hydrophilic character than hydrophobic areas, similar to the SOX3 protein from C. auratus (Fig. 3B).

\section{Expression pattern of MaSox3 in different development stages and tissues}

To analyze MaSox3 expression levels in different developmental tissue, we used quantitative real-time reverse transcription PCR (qRT-PCR). We found that MaSox3transcripts were highly expressed in gonads $(p<0.01)$; moderately in brain, liver, and heart; and less in the kidney (Fig. 4A). Then we analyzed transcripts during different stages of development. We found that MaSox3 transcripts initially exhibit low detection levels during gastrula stage of embryo, but then rapidly increase, reaching maximum levels at neurula stage $(p<0.01)$. After reaching its maximum, MaSox3 transcripts gradually decrease, maintaining stable expression levels until the yolk-sac absorption stage we examined (Fig. 4B).

\section{In situ Hybridization}

To examine the distribution of MaSox3 transcript distribution during embryogenesis, we carried out whole-mount in situ hybridization (WISH) using high stringency conditions.

Fig. 4. Expression analysis by quantitative real-time RT-PCR of MaSox3 in adult tissues (A) and developing embryo (B). All data were expressed as mean \pm SEM $(n=9)$. Asterisks ( $\left.{ }^{*}\right)$ indicate means with significantly higher Sox3 mRNA levels $\left.{ }^{* *} p<0.01 ;{ }^{*} p<0.05\right)$.

\section{$A$}
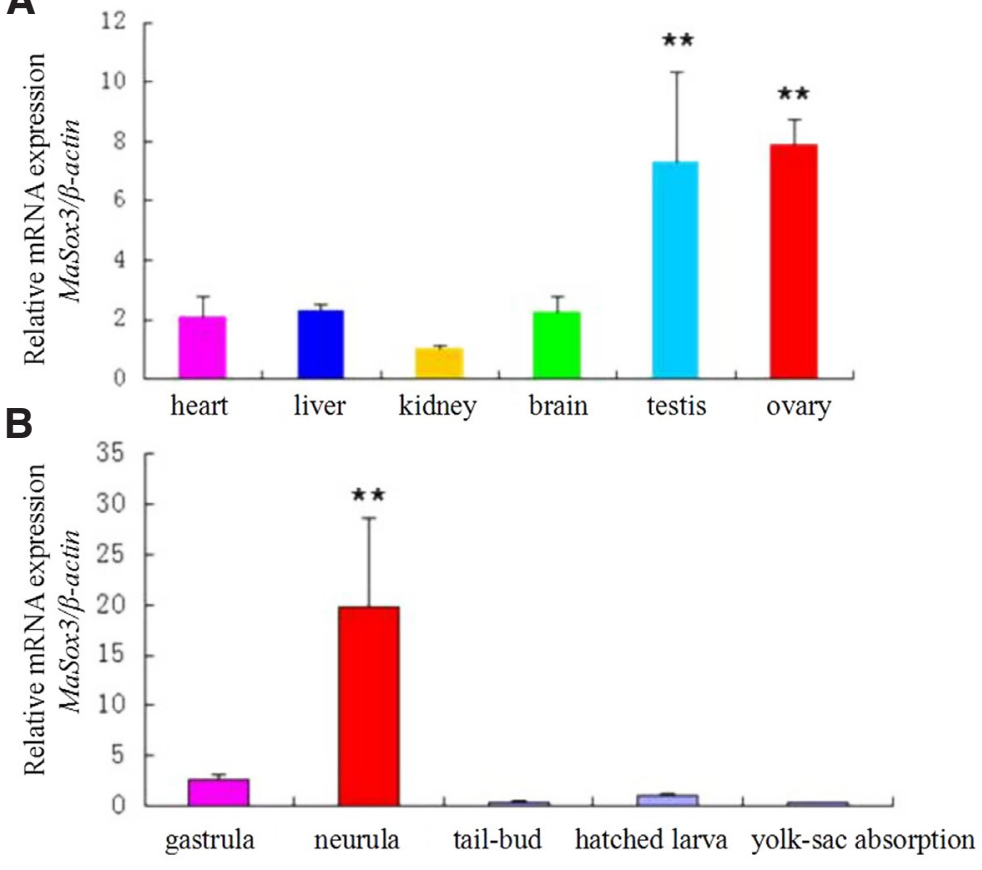

MaSox3 mRNA first accumulated in the eight-cell stage (Fig. 5A), and then accumulated in the hemisphere after the entry into blastula stage (Fig. 5C). After entry into neurula stage, MaSox3 was expressed broadly in the central nervous system (Fig. 5 E,F). At 20-26 hpf, MaSox3 was still broadly expressed in the central nervous system including the optic vesicle, which becomes the future retina. MaSox3 expression level was low in the forebrain-midbrain

gastrula neurula tail-bud hatched larva yolk-sac absorption 
A

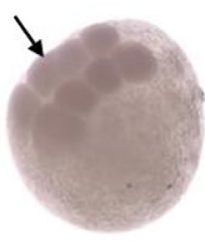

D

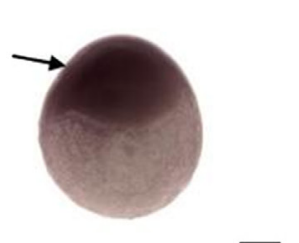

G
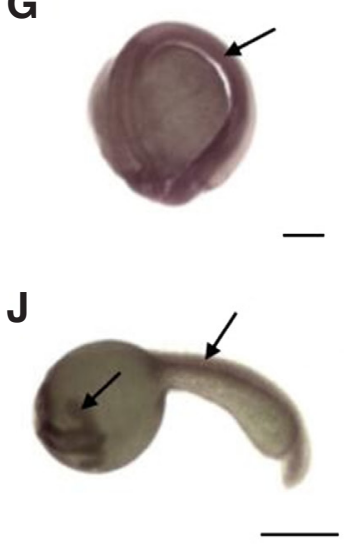

B

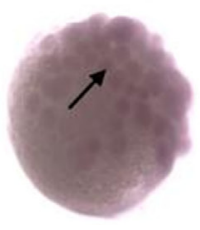

E

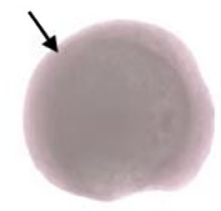

H

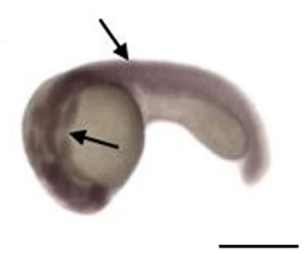

C

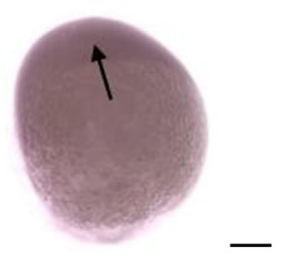

$\mathbf{F}$

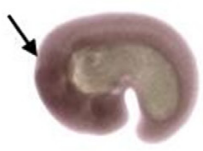

important functions during embryo development, embryonic and adult neurogenesis, sex differentiation, and gonadal development (Rogers et al., 2013; Cheah and Thomas, 2015). Here, we have isolated and characterized the full-length cDNA sequence of a Sox3 homolog, MaSox3 in M. anguillicaudatus. Similar to other reported Sox genes, MaSox 3 contains the highly conserved HMG-box DNA binding domain, suggesting it is structurally conserved during vertebrate evolution (Focareta and Cole, 2016).

Additionally, qRT-PCR result shows that MaSox3 is widely expressed during $M$. anguillicaudatus embryonic development, from gastrula stage to yolk-sac absorption stage, consistent with Japanese flounder and zebrafish, but different from the red-spotted grouper (Yao et al., 2003; Gao et al., 2015). WISH results showed that MaSox3 is consistently expressed during embryogenesis. Especially, MaSox 3 is expressed throughout the pluripotent ectodermal cells of blastula embryos, which is associated with germ layer differentiation, histogenesis and organogenesis occur during embryonic development. These results suggested that Sox3 is involved in early embryonic development process (Rogers et al., 2013).

Previous studies have revealed that Sox3 regulation is region-specific in the developing nervous system, and plays different roles in the dorsal telencephalon and hypothalamus (Rogers et al., 2013). In zebrafish, knockdown of Sox3 reduces the size of the central nervous system and subsequently inhibits some aspects of neurogenesis (Dee et al., 2008). Our study suggests that the maximum level of MaSox 3 occurs during the neurula stage of embryogenesis. Additionally, MaSox3 is highly expressed in brain tissue, similar to what is seen in Japanese flounder (Gao et al., 2015). Moreover, in situ hybridization results revealed that the highest

Fig. 5. Whole mount in situ hybridization analysis of MaSox3 during embryogenesis. (A) Eight-cell stage (1 h post fertilization, hpf); (B) multicellular stage (2 hpf); (C) blastula stage (3 hpf); (D) gastrula stage (5 hpf); (E) neurula stage (11 hpf); (F) tail-bud formed stage (17 hpf); (G) otic vesicle formation stage (20 hpf); (H) otic vesicle formation lateral view $(20$ hpf); (I) otic vesicle formation dorsal view (20 hpf); (J) otic vesicle formation ventral view (20 hpf); (K) hatched larva (26 hpf); (L) hatched larva stage dorsal view (26 hpf). Arrow head show obvious hybrid signals. Scale bars (A-G), $200 \mu \mathrm{m} ;(H-L), 300 \mu \mathrm{m}$.

and midbrain-hindbrain boundaries, but strong expression was observed in the otic vesicle and viscera (Fig. $5 \mathrm{G}-\mathrm{L}$ ).

To elucidate localization of MaSox3mRNA, we performed in situ hybridization (ISH) on testis, ovary and brain sections. In the testis, primordial germ cells develop first into spermatogonia, then into spermatocyte and finally into spermatid. We found accumulation of our probe in both the spermatocytes and spermatids (Fig. 6A). In the ovary, MaSox3RNA signal was strongly observed in primary oocyte and previtellogenic oocyte. As the tissue developed, the probe signal decreased, and no signal was detected once the yolk in the previtellogenic oocyte cytoplasm was full (Fig. 6C). In the brain, we observed a strong signal in the particle cell layer, but no obvious signal was observed in the molecular cell layer (Fig. 6E). All results were compared to a MaSox3 sense RNA probe, which did not display a signal in the ovary, testis and brain (Fig. 6 B,D,F).

\section{Discussion}

Previous studies have revealed that Sox 3 is widely expressed in the early central nervous system of vertebrates, and performed

expression of MaSox3 appeared in brain particle cell layer, and broadly expressed in central nervous system including the midbrain and hindbrain. All of these results suggest that Sox3 is critical for neural development in vertebrates (McAninch and Thomas, 2014).

Sox 3 is reported to be an analog of SRY in testis and associated with mammalian testis developmentand differentiation (Rajakumar and Senthilkumaran, 2014). Also, Sox3 has been found to be associated with male sex differentiation in Oryzias dancena (Takehana et al., 2014). The present study shows MaSox 3 is highly expressed in the ovary and testis, and does not exhibit a dimorphic expression pattern. In species-rich fish, diverse expression profiles reveal a distinct Soxprotein role in either testicular or ovarian development, such as red-spotted grouper, black porgy and catfish (Rajakumar and Senthilkumaran, 2014; Gao et al., 2015). The gonad section using in situ hybridization revealed that a positive probe signal was observed in primary spermatocyte cell, primary oocyte and previtellogenic oocyte. In mouse, Sox3 has been demonstrated to be important for oocyte development, testis differentiation as well as gametogenesis (Weiss et al., 2003). Similarly, MaSox3 was not expressed during gonadal determination but becomes expressed 


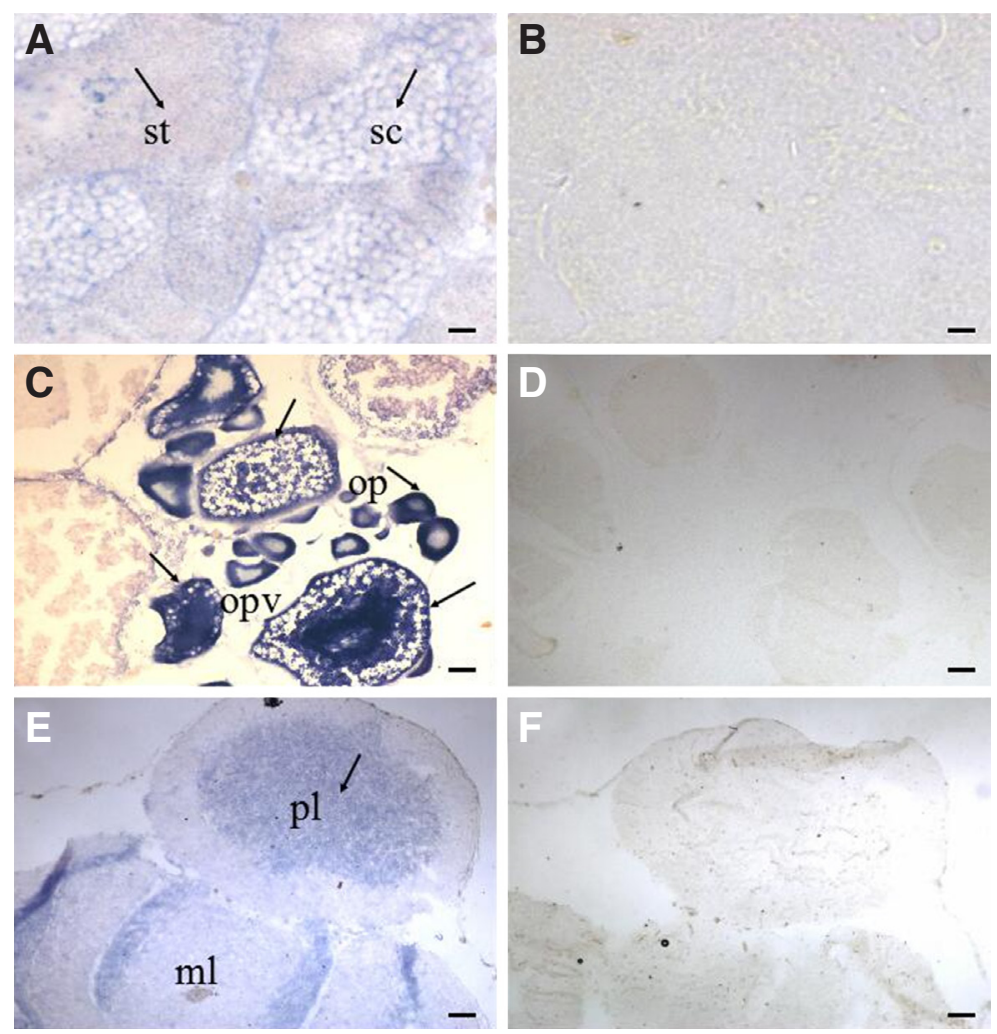

Fig. 6. Expression analysis of Sox3 by in situ hybridization to tissue sections. Testis (A,B), ovary (C,D), brain (E, F). Anti-sense Sox3 (A, C,E) and Sense probing as control (B,D,F). SC, spermatocyte; st, spermatid; op, primary oocyte stage; opv, previtellogenic oocyte stage; pl, granulosa cell layer; $\mathrm{ml}$, molecular cell layer. Positive signals are shown as black arrows. Scale bars, $50 \mu \mathrm{m}$.

during oocyte development and male testis differentiation and gametogenesis.

Gonad development and maturity is affected by many factors such as gene expression and environmental cues, which involve a complex network of signal molecules. For instance in fish, gonad development is regulated primarily by the hypothalamic-pituitary-gonadal (HPG) axis of the neuroendocrine system (Chen et al., 2013). Our study suggests that MaSox3 gene may play an important roles during early embryonic development, the formation and development of both the nervous system and gonad development, especially in complex regulatory mechanisms associated with the HPG axis. These results therefore provide fundamental information regarding the function of Sox3 in teleost fish. Further studies must be carried out to continue elucidating the precise role and mechanism of Sox3 in fish, especially in regards to complex regulatory mechanisms associated with the HPG axis.

\section{Materials and Methods}

\section{Samples}

Adult M. anguillicaudatus were collected from the wetlands in the old course of the Yellow River, Yanjin County (Henan, China). Animal maintenance and handling procedures followed the recommendations of the Association of Animal Behaviour and national regulations (Elsevier, 2012). Fish spawning and spermiation were artificially induced using intramuscular injection of human chorionic gonadotropin hormone. Three groups consisting of 15-20 zygotic embryos were sampled at the following developmental stages: gastrula, neurula, tail-bud formed, hatched larva and yolk-sac absorption stages were sampled. Adult individuals were acclimatized in a laboratory environment for $48 \mathrm{~h}$ before treatment, and then six individuals were randomly selected for the sampling the following tissues: heart, liver, kidney, brain and gonads (ovary and testis). Tissue samples were immediately frozen in liquid nitrogen, and then embryo and larval samples were immersed in $1 \mathrm{~mL}$ of RNAwait liquid (Solarbio, Beijing, China) and stored at $-80^{\circ} \mathrm{C}$ until RNA isolation.

\section{RNA extraction and cDNA synthesis}

For total RNA extraction, mature adult tissues or embryos/larvae were homogenized and subjected to TRIzol reagent (RNA Extraction Kit, Invitrogen, CA, USA) according to the manufacturer's manual. First-strand cDNA preparation was carried out with Prime Script reverse transcriptase (Takara, Dalian, Japan).

\section{Molecular cloning of Sox3 gene}

Sox3 sequences were retrieved from GenBank (www.ncbi.nlm. nih.gov) and multiply aligned by DNAMAN. Degenerate primers were designed based on the conserved regions of the HMG domain (Table 1 ), and then the resulting PCR product was sequenced. Based on the HMG-box sequence of the MaSox3 gene, gene-specific primers were designed for the RACE (Table 1). 3' RACE cDNA and 5' RACE cDNA were synthesized using the RACE Core Set (TaKaRa) PCR product was cloned into the pGEM-T Easy Vector (TaKaRa), detected, and sequenced.

\section{Sequence analysis}

The full-length cDNA sequence of MaSox 3 was assembled using overlapping regions of each fragment. Both the nucleotide sequence and deduced amino acid sequence were compared with their homologous in other species using the BLAST program (http://www.ncbi. nlm.nih.gov/BLAST/). Multiple alignment of MaSox3 was performed with Clustal Omega (http://www.ebi.ac.uk/Tools/msa/). The potential protein domain was predicted via SMART server (http://smart.emblheidelberg.de/). A phylogenetic tree was constructed by Molecular

Evolution Genetics Analyses version 6.0 using neighbor-joining method. The evolutionary distance between SoxB sequences was calculated using p-distance and gaps were removed by pair-wise detection, using default parameters. To evaluate the tree topological stability, 1000 bootstraps replicates were made. The Physico-chemical parameters of the deduced MASOX3 protein were analyzed by ProtParam tool at ExPASy (http://expasy.org/tools/protparam.html). The secondary structures were predicted with SOPMA software (https://npsa-prabi.ibcp.fr/cgi-bin/npsa_automat. $\mathrm{pl}$ ?page=/NPSA/npsa_ sopma.html). The three-dimensional structure of deduced MASOX3 protein was predicted by Swiss-Model (https://swissmodel.expasy.org/). The ProtScale program (http://expasy.org/tools/protscale. $\mathrm{html}$ ) was used to analyze the protein hydropathy profile.

TABLE 1

\section{PRIMERS USED IN GENE CLONING AND RT-PCR}

\begin{tabular}{lll} 
Usage & Primer name & Primer sequence $\left(\mathbf{5}^{\prime} \rightarrow \mathbf{3}^{\prime}\right)$ \\
\hline DegeneratePCR & HMG-F & ATGTA ( T/C ) A(A/G)CATGATGGA(A/G)ACCG \\
& HMG-R & CTTTCTT(GC)AGCA(GA)(CG)GTCTTGGTC \\
3'RACE & 3'Sox3 outer & CCAAGCGGTTACGAGCCAT \\
& 3'Sox3 inner & GAAGACCAAGACCGTGCTCAAG \\
5'RACE & 5'Sox3 outer & GGCACCGAGACGCTTGCT \\
& 5'Sox3 inner & CTGATTTCGGAGTTGTGC \\
Quantitative real-time & Sox3-F & CGTGCTCAAGAAAGACAAG \\
RT-PCR & Sox3-R & ATGCTGGGATGCTGAGGGTAG \\
& $\beta$-actin-F & AGAGAGAATTGTCCGTGAC \\
& $\beta$-actin-R & GCCAATGGTGATGACCTGT \\
ISH & ISH-Sox3-F & CGTGCTCAAGAAAGACAAG \\
& ISH-Sox3-R & CTGCGTGTATGCTGGTGAC \\
\hline
\end{tabular}




\section{MaSox3 expression analysis with qRT-PCR}

To further quantify the expressions of MaSox 3 in various tissues and different development stages, qRT-PCR were performed using the specific primers shown in Table 1. Reverse transcription products of each sample were properly diluted as templates, and three biological replicates were tested and each sample was assayed in triplicate to ensure reproducibility. $\beta$-actin was used as control to normalize data from different samples (Xia et al., 2017). The $2^{-\Delta \Delta C t}$ method was used to analyze the expression levels of MaSox3 (Livak et al., 2001). All data were expressed as the mean \pm standard error of the mean (SEM). The program SPSS V.16 was used for the one-way analysis of variance. And $p$-values of $<0.01$ were considered as statistically significant.

\section{In situ hybridization}

The fragment amplified by $3^{\prime}$ RACE was cloned into the pGEM-T vector (Promega) and linearized as template for in vitro transcription to generate antisense or sense digoxigenin-UTP labeled RNA probes (DIG RNA labeling kit; Roche, shanghai). WISH and ISH were performed as previously described with minor modifications (Xia et al., 2013; Gao et al., 2015). The sections were observed and photographed with a Nikon Eclipse Ti-U microscope (Nikon, Tokyo, Japan).

\section{Acknowledgments}

This work is supported by grants from the National Natural Science Foundation of China (no. 31200923, no. U1404330), Young Core Instructor Foundation of Henan Normal University (no. 5101049470610) and Program for Innovative Research Team (in Science and Technology) in University of Henan Province (no. 17IRTSTHN017).

\section{References}

BOWLES J, SCHEPERS G, KOOPMAN P (2000). Phylogeny of the SOX family of developmental transcription factors based on sequence and structural indicators. Dev Biol 227: 239-255.

CHEAH P S, THOMAS Q P (2015). SOX3 expression in the glial system of the developing and adult mouse cerebellum. Springerplus 4: 400 .

CHEN J, HU W, ZHU Z Y (2013). Research progress of fish reproduction and development regulation. Chinese Sci Bull 58: 103-114.

DEE C T, HIRST C S, SHIH Y H, TRIPATHI VB, PATIENT R K, SCOTTING P J (2008). Sox3 regulates both neural fate and differentiation in the zebrafish ectoderm. Dev Biol 320: 289-301.

FOCARETA L, COLE A G (2016). Analyses of Sox-B and Sox-E Family Genes in the Cephalopod Sepia officinalis: Revealing the Conserved and the Unusual. PLOS One 11: e0157821.
GAO J, LI P, ZHANG W, WANG Z, WANG X, ZHANG Q (2015). Molecular Cloning, Promoter Analysis and Expression Profiles of the sox3 Gene in Japanese Flounder, Paralichthys olivaceus. Int J Mol Sci 16: 27931-27944.

GIMELLI G, GIMELLI S, DIMASI N, BOCCIARDI R, DI BATTISTA E, PRAMPARO T, ZUFFARDI O (2007). Identification and molecular modelling of a novel familia mutation in the SRY gene implicated in the pure gonadal dysgenesis. Eur $J$ Hum Benet 15: 76-80.

KAMACHIY, UCHIKAWAM, COLLIGNON J, LOVELL-BADGER, KONDOHH(1998) Involvement of Sox 1, 2 and 3 in the early and subsequent molecular events of lens induction. Development 125: 2521-2532.

LARONDA M M, JAMESON J L (2011). Sox3 functions in a cell-autonomous manner to regulate spermatogonial differentiation in mice. Endocrinology 152: 1606-1615.

LIVAK K J, SCHMITTGEN T D (2001). Analysis of relative gene expression data using real-time quantitative PCR and the 2 (-Delta Delta C (T)) method. Methods 25: 402-408.

MCANINCH D, THOMAS P (2014). Identification of Highly Conserved Putative Developmental Enhancers Bound by SOX3 in Neural Progenitors Using ChIPSeq. PLoS One 9: e113361.

RAJAKUMAR A, SENTHILKUMARAN B (2014). Expression analysis of sox3 during testicular development, recrudescence, and after hCG induction in catfish, clarias batrachus. Sex Dev 8: 376-386.

ROGERS N, CHEAH P S, SZAREK E, BANERJEE K, SCHWARTZ J, THOMAS P (2013). Expression of the murine transcription factor SOX3 during embryonic and adult neurogenesis. Gene Expr Patterns 13: 240-248.

SINCLAIR A H, BERTA P, PALMER M S, HAWKINS J R, GRIFFITHS B L, SMITH $M$ J, FOSTER J W, FRISCHAUF A M, LOVELL-BADGE R, GOODFELLOW P N (1990). A gene from the human sex-determining region encodes a protein with homology to a conserved DNA-binding motif. Nature 346: 240-244.

TAKEHANA Y, MATSUDA M, MYOSHO T, SUSTER M L, KAWAKAMI K, SHIN I T, KOHARA Y, KUROKI Y, TOYODA A, FUJIYAMAA, HAMAGUCHI S, SAKAIZUM M, NARUSE K (2014). Co-option of Sox 3 as the male-determining factor on the y chromosome in the fish Oryzias dancena. Nat Commun 5: 4157.

WATANABE M, KAWASAKI K, KAWASAKI M, PORTAVEETUS T, OOMMEN S, BLACKBURN J, NAGAI T, KITAMURA A, NISHIKAWA A, KODAMA Y, TAKAG R, MAEDA T, SHARPE PT, OHAZAMA A (2016). Spatio-temporal expression of Sox genes in murine palatogenesis. Gene Expr Patterns 21: 111 -118.

WEISS J, MEEKS J J, HURLEY L, RAVEROT G, FRASSETTO A, JAMESON J L, (2003). Sox 3 is required for gonadal function, but not sex determination, in males and females. Mol Cell Biol 23: 8084-8091.

XIA X, CHEN J, ZHANG L, DU Q, SUN J, CHANG Z (2013). Molecular cloning and mRNA expression pattern of Sox10 in Paramisgurnus dabryanus. Mol Biol Rep 40: 3123-3134.

XIAX, HUO W, WAN R, XIA X, DU Q, CHANG Z (2017). Identification of housekeeping genes as references for quantitative real time RT-PCR analysis in Misgurnus anguillicaudatus. J Genet Doi. 10.1007/s12041-017-0845-0

YAO B, ZHOU L, GUI J F (2003). Studies on cDNA cloning and temporal and spatia expression of sox3 gene in grouper epinephelus coioides. High Technol Lett 13: $74-81$. 


\section{Further Related Reading, published previously in the Int. J. Dev. Biol.}

\section{Expression of Sox genes in tooth development}

Katsushige Kawasaki, Maiko Kawasaki, Momoko Watanabe, Erik Idrus, Takahiro Nagai, Shelly Oommen, Takeyasu Maeda, Nobuko Hagiwara, Jianwen Que, Paul T. Sharpe and Atsushi Ohazama

Int. J. Dev. Biol. (2015) 59: 471-478

https://doi.org/10.1387/ijdb.150192ao

Expression of Sox family genes in early lamprey development

Benjamin R. Uy, Marcos Simoes-Costa, Tatjana Sauka-Spengler and Marianne E. Bronner

Int. J. Dev. Biol. (2012) 56: 377-383

https://doi.org/10.1387/ijdb.113416bu

Cloning and developmental expression of the soxB2 genes, sox14 and sox21, during Xenopus laevis embryogenesis Doreen D. Cunningham, Zhuo Meng, Bernd Fritzsch and Elena Silva Casey

Int. J. Dev. Biol. (2008) 52: 999-1004

https://doi.org/10.1387/ijdb.082586dc

Interplay of Pax6 and SOX2 in lens development as a paradigm of genetic switch mechanisms for cell differentiation

Hisato Kondoh, Masanori Uchikawa and Yusuke Kamachi

Int. J. Dev. Biol. (2004) 48: 819-827

http://www.intjdevbiol.com/web/paper/041868hk

Roles of Sox factors in neural determination: conserved signaling in evolution? Y Sasai

Int. J. Dev. Biol. (2001) 45: 321-326

http://www.intjdevbiol.com/web/paper/11291862

Characterization and early embryonic expression of a neural specific transcription factor XSOX3 in Xenopus laevis

R Penzel, R Oschwald, Y Chen, L Tacke and H Grunz

Int. J. Dev. Biol. (1997) 41: 667-677

http://www.intjdevbiol.com/web/paper/9415486

5 yr ISI Impact Factor $(2013)=2.879$
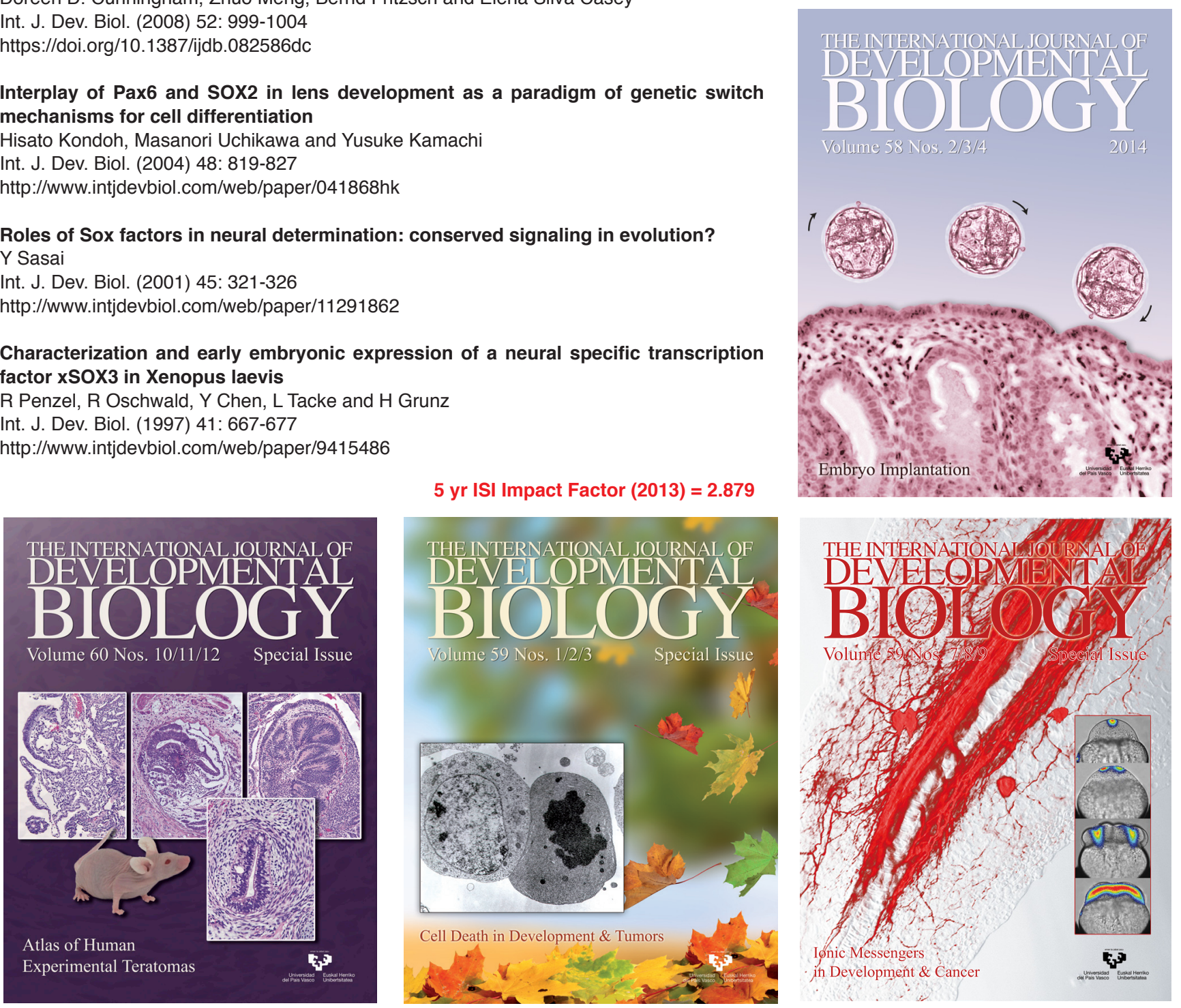